\title{
IDENTIFIKASI AKTIVITAS MENDIRIKAN BANGUNAN DALAM PEMANFAATAN RUANG DI KORIDOR JALAN KOM. YOS SUDARSO PONTIANAK
}

\author{
Zairin Zain \\ Program Studi Arsitektur Fakultas Teknik Universitas Tanjungpura, Pontianak \\ zairin.zain@untan.ac.id
}

\author{
Azwar Fahmie \\ Program Magister Teknik Sipil Universitas Tanjungpura, Pontianak \\ azwarfahmie04@gmail.com
}

\begin{abstract}
Abstrak
Setiap kota tumbuh dan berkembang sesuai dengan potensi dan dinamika yang ada di dalamnya. Agar perkembangan kota tersebut dapat terarah dan teratur diperlukan suatu pedoman bagi kegiatan pembangunan dan pemanfaatan ruang. Pedoman bagi kegiatan pembangunan dan pemanfaatan ruang kota tersebut adalah Rencana Tata Ruang Wilayah Kota (RTRW) serta peraturan yang terkait dengan aktivitas pemanfaatan ruangnya.Dalam RTRW Kota Pontianak, masing-masing wilayah merupakan bagian wilayah kota yang menjadi fokus perencanaan. Perkembangan wilayah akan membawa pengaruh terhadap pemanfaatan ruang yang ada. Hal ini dapat dilihat dari beberapa fenomena yang terjadi, yaitu adanya penyimpangan terhadap pemanfaatan ruang yang sudah ditetapkan dalam rencana tata ruang. Kondisi ini dapat dilihat dengan mudah pada ruas-ruas jalan utama yang menjadi cerminan wajah Kota Pontianak. Pada ruas jalan utama masih banyak terdapat bangunan yang berdiri tidak sesuai dengan aturan rencana tata ruang dan tata bangunan yang ada. Akibat lebih jauh dari kondisi ini adalah penataan bangunan sebagai inti fisik kota terkesan kurang teratur dan berkembang tidak sesuai harapan.

Tujuan penelitian ini adalah melakukan identifikasi terhadap pemanfaatan ruang bagi aktivitas mendirikan bangunan di sepanjang koridor Jalan Kom Yos Sudarso Pontianak yang merupakan salah satu jalan utama di Kota Pontianak untuk melihat kesesuaiannya dengan peraturan tata ruang dan bangunan yang berlaku khususnya peraturan yang berkaitan dengan perencanaan RMJ dan GSB pada kawasan tersebut.Penelitian ini menggunakan desain riset deskriftif dengan survei sebagai instrumen penelitian, yaitu dengan melakukan obsevasi dan pengamatan langsung dilapangan untuk memperoleh data primer berkaitan dengan jumlah dan karakteristik bangunan di sepanjang koridor Jalan Kom Yos Sudarso Pontianak. Analisis yang digunakan adalah analisis deskriftif untuk melihat frekuensi dan pola sebaran data yang dimati. Dari analisis tersebut maka dapat diketahui gambaran tentang frekuensi, kecenderungan serta pola sebaran aktivitas mendirikan bangunan di sepanjang koridor jalan Kom Yos Sudarso Pontianakterhadap penerapan peraturan tata ruang dan bangunan pada wilayah penelitian.

Hasil identifikasi didapat 216 unit bangunan atau 17,2\% terkena perencanaan RMJ dan sebagian besar adalah bangunan dengan fungsi usaha. Sementara itu, bangunan yang tidak sesuai dengan penataan GSB pada wilayah penelitian ini sebesar 825 unit bangunan atau mencapai 65,6\% dari seluruh bangunan yang diamati. Fungsi bangunan yang paling banyak melanggar aturan penataan GSB adalah bangunan dengan fungsi usaha serta bangunan yang berfungsi sebagai hunian dan usaha yang mencapai $41,9 \%$ dan $14,3 \%$ dari total bangunan yang di amati.
\end{abstract}

Kata-Kata Kunci : Pemanfaatan Ruang, Aktivitas Mendirikan Bangunan, Koridor Jalan 


\title{
IDENTIFICATION ON THE ACTIVITIES OF BUILDING CONSTRUCTION WITH REGARD TO SPATIAL USE AT KOM YOS SUDARSO'S STREET CORRIDORS PONTIANAK
}

\begin{abstract}
Every city grows and develops according to the potential and dynamics the city has in itself. For the development of the city to be orderly and well directed, a guideline is needed for development activities and spatial utilization. Such a guideline for the development and utilization of urban space is known as Urban Spatial Plans (RTRW) as well as regulations related to the activities of spatial utilization. In the RTRW of Pontianak City, each region is a part of the city that becomes the focus of planning. The development of a region will obviously affect the utilization of existing space. This can be seen from several phenomena that occur, namely deviation against space utilization that has been defined in the spatial plan. This condition can easily be seen on the sections of main roads that constitute as reflection of the face of Pontianak City. On the main road, sections there are still found many buildings that are not in accordance with the existing spatial plan and building layout. A further consequence of such a condition is that the arrangement of buildings as the physical core of the city seems to be less organized and develops not as it had been expected to be.

The purpose of this study is to identify the use of space for the activity of building constructions along the corridor of Kom Yos Sudarso Pontianak street which is one of the main roads in Pontianak City and to see if they are in compliance with the existing spatial and building regulations, particularly the regulations relating to the RMJ plans (Street Owned Space) and GSB (Building Border Line) on the area in question. This research uses descriptive research design with a survey as its main research instrument by conducting observation and direct field observation to get the primary data related to the numbers and characteristics of the buildings along the corridor of Kom Yos Sudarso Street, Pontianak. The analysis used is descriptive analysis to see the frequency and pattern of data distribution being observed. From the analysis, it could be seen that the description of the frequency, tendency and patterns of building activity distribution along the corridor of Kom Yos Sudarso Street Pontianak with regard to the implementation of spatial and building regulations in the researched area.

Identification results obtained 216 building units or $17.2 \%$ exposed to planning RMJ and as large is a building with business functions. Meanwhile, buildings that are inconsistent with the GSB structuring in this research area are 825 units of buildings or $65.6 \%$ of all buildings observed. Building functions that most violate GSB structuring rules are buildings with business functions as well as buildings that serve as occupancy and businesses that reach $41.9 \%$ and $14.3 \%$ of the total buildings observed.
\end{abstract}

Keywords: Space Utilization, Building Activity, Road Corridor

\section{Pendahuluan}

Dalam Undang-Undang No. 28 Tahun 2002 Tentang Bangunan Gedung disebutkan bahwa bangunan adalah tempat manusia melakukan kegiatan, yang memiliki perananan dalam pembentukan watak, perwujudan produktifitas, serta jati diri manusia. Oleh karena itu, penyelenggaraan bangunan mesti diatur dan dibina demi kelangsungan dan peningkatan kehidupan serta penghidupan masyarakat. Selain itu dengan dengan penyelenggaraan bangunan yang baik akan mampu untuk mewujudkan bangunan yang fungsional, andal, berjati diri, serta seimbang, serasi, dan selaras dengan lingkungannya.

Bangunan merupakan salah satu wujud fisik pemanfaatan ruang, oleh karenanya dalam pembangunan infrastruktur khususnya dalam pembangunan gedung akan memberikan dampak 
terhadap pemanfaatan ruang pada suatu kawasan. Pengendalian pemanfaatan ruang merupakan bagian yang tidak terpisahkan dari proses penataan ruang. Pemanfaatan ruang dibanyak daerah di Indonesia, dalam pelaksanaan sering atau tidak selalu sejalan dengan rencana tata ruang yang telah ditetapkan.

Kota Pontianak adalah salah satu kota di Indonesia yang terus melakukan pembangunan infrastruktur termasuk dalam pembangunan gedung. Perkembangan yang terjadi berpengaruh terhadap pemanfaatan ruang yang ada. Hal ini dapat dilihat dari fenomena yang ada, yaitu terjadinya berbagai penyimpangan terhadap pemanfaatan ruang yang sudah ditetapkan dalam Peraturan Daerah Kota Pontianak No. 2 Tahun 2013 tentang RTRW Kota Pontianak. Kondisi ini dapat dilihat dengan mudah pada ruas-ruas jalan utama yang menjadi cerminan wajah Kota Pontianak. Di berbagai ruas jalan utama masih banyak bangunan yang berdiri tidak sesuai dengan aturan rencana tata ruang dan tata bangunan yang ada. Akibat lebih jauh dari kondisi ini adalah penataan bangunan sebagai inti fisik kota terkesan kurang teratur dan berkembang tidak sesuai harapan.

Untuk melihat gambaran mengenai aktivitas mendirikan bangunan di Kota Pontianak dengan segala permasalahannya, maka penulis tertarik untuk mengadakan penelitian secara mendalam pada satu wilayah di Kota Pontianak. Wilayah yang diamati dan dijadikan fokus penelitian adalah wilayah terbangun di sepanjang Koridor Jalan Kom. Yos Sudarso Kota Pontianak. Lokasi penelitian ini dipilih karena merupakan salah satu wilayah dengan koridor jalan terpanjang yang ada di Kota Pontianak dengan pemanfaatan ruang terbangun yang heterogen, baik dari guna dan fungsi bangunan, ketinggian bangunan, serta dari konstruksi bangunan yang digunakan. Dari hasil pengamatan yang dilakukan terlihat bahwa aktivitas mendirikan bangunan khususnya bangunan dengan fungsi usaha terutama kios menunjukan perkembangan yang sangat dominan dan tidak terkendalikan yang terkesan tidak sesuai dengan ketentuan pemanfaan ruang yang sudah ditetapkan. Permasalahan yang terjadi adalah ketidaksesuaian antara rencana dengan pemanfaatan ruang yang ada, sehingga mengakibatkan kota berkembang kurang sesuai dengan perencanaan yang ada serta terkesan kurang teratur dan rawan dari segi keamanan maupun kesehatan. Kondisi ini apabila dibiarkan akan berdampak negatif terhadap penataan ruang, seperti tidak terpenuhinya standar kesehatan, keamanan, kenyamanan dan keserasian dari segi arsitektur maupun menurunnya kualitas lingkungan.

Berawal dari permasalah tersebut maka menarik diadakan penelitian untuk mengetahui seperti apakah sesungguhnya fakta mengenai aktivitas mendirikan bangunan di wilayah penelitian. Tujuan penelitian ini adalah untuk melakukan identifikasi terhadap aktivitas mendirikan bangunan di sepanjang koridor jalan Kom. Yos Sudarso yang merupakan salah satu koridor jalan terpanjang di Kota Pontianak. Adapun identifikasi tersebut terkait dengan aktivitas mendirikan bangunan untuk bangunan yang sudah terbangun yang meliputi fungsi bangunan, kegunaan bangunan, jumlah lantai bangunan serta jenis konstruksi bangunan. Selain itu penulis ingin mengamati secara mendalam mengenai kondisi eksisting bangunan dengan penerapan perizinan bangunan khususnya kesesuaian bangunan terhadap peraturan Ruang Milik Jalan (RMJ) dan GSB (Garis Sempadan Bangunan) di lokasi pengamatan sesuai peraturan bangunan Gedung Kota Pontianak No. 3 Tahun 2008.

\section{Kajian Pustaka}

Dalam Undang-Undang No. 26 Tahun 2007 tentang Penataan Ruang di sebutkan bahwa bangunan adalah salah satu wujud fisik pemanfaatan ruang, oleh karenanya dalam pembangunan infrastruktur khususnya dalam pembangunan gedung akan memberikan dampak terhadap pemanfaatan ruang pada suatu kawasan. Pemanfaatan ruang dibanyak daerah di Indonesia, dalam pelaksanaan sering atau tidak selalu sejalan dengan rencana tata ruang yang telah ditetapkan.Perencanaan kota merupakan aktivitas merencanakan suatu lingkungan tertentu, yang lebih luas dari pada perencanaan lahan atau fisik, karena mempertimbangkan semua faktor fisik, tata 
guna lahan, ekonomi, politik, administratif dan sosial yang mempengaruhi wilayah kota (Nurmandi, 1999).

Menurut Yahya (2015), Penataan bangunan dan lingkungan dalam suatu kawasan maupun suatu koridor tidak boleh terlepas dari rencana tata ruang yang sudah ada. Perkembangan kota yang pesat sebagai akibat dari aktivitas ekonomi yang tinggi, menuntut kejelian dan kearifan dalam menata bangunan dan lingkungan.

Menurut Wardhana dan Haryanto (2016), rangkuman beberapa teori menjelaskan beberapa tempat lebih disukai untuk aktivitas ekonomi yang menarik karena lokasi tersebut memiliki sumber daya, pasar, tenaga kerja, dan sebagainya sehingga membentuk pusat pertumbuhan alami dan berkembang lebih cepat dibandingkan daerah lain.

Menurut Permen PU Nomor 06/PRT/M/2007 tentang Pedoman Umum Rencana Tata Bangunan dan Lingkungan, intensitas pemanfaatan ruang adalah Intensitas Pemanfaatan Lahan adalah tingkat alokasi dandistribusi luas lantai maksimum bangunan terhadap lahan/tapak peruntukannya.. Intensitas pemanfaatan ruang atau penggunaan lahan ini merupakan variabel untuk melihat elemen yang mempengaruhi morfologi kota yaitu bentuk dan massa bangunan.Dalam Penjelasannya, Permen PU Nomor 06/PRT/M/2007 juga menyebutkan Pemanfaatan ruang dimaksudkan untuk Mendapatkan distribusi berbagai elemen intensitas lahan pemanfaatan lahan (Koefisien Dasar Bangunan, Koefisien Lantai Bangunan, Koefisien Daerah Hijau, dan Koefisien Tapak Besmen) yang dapat mendukung berbagai karakter khas dari berbagai subarea yang direncanakan. Selain itu, pemanfaatan ini akan Merangsang pertumbuhan kota dan berdampak langsungpada perekonomian kawasan.

Koridor jalan merupakan jalan inspeksi tersebut banyak dibangun kios-kios, toko kecil dan ruko untuk kegiatan komersial. Permasalahan yang terjadi mulai dari perubahan peruntukan lahan yang juga menimbulkan persoalan perizinan, status kepemilikan tanah, dan juga dampaknya bagi pertanian dan aktivitas lain selain komersial. Kondisi fisik koridor yang tidak sesuai aturan seperti sempadan jalan, lahan parkir dan letak bangunan (Irawati dan Haryanto, 2015).

Sesuai dengan Perda Kota Pontianak No. 3 tahun 2008 tentang Bangunan Gedung dijelaskan bahwa Izin mendirikan bangunan adalah izin untuk mendirikan bangunan yang meliputi kegiatan penelitian tata letak dan desain bangunan, pengawasan peIaksanaan pembangunannya agar tetap sesuai dengan rencana tata ruang yang berIaku dan rencana teknis bangunan dengan tetap memperhatikan Koefisien Dasar Bangunan (KDB), Koefisien Luas Bangunan (KLB), Koefisien Ketinggian Bangunan (KKB) meliputi pemeriksaan dalam rangka memenuhi syarat-syarat keselamatan bagi yang menempati bangunan tersebut.

\section{Metode Penelitian}

Penelitian ini menggunakan desain riset deskriptif dengan survei sebagai instrumen penelitian. Desain penelitian dalam penelitian ini dilakukan dengan studi dan survey lapangan yang bersifat eksplorasi dan deskriptif. Penelitian ini memberikan gambaran secara objektif tentang keadaan sebenarnya dari objek yang diteliti. Tujuan penelitian ini adalah melakukan identifikasi terhadap pemanfaatan ruang bagi aktivitas mendirikan bangunan di sepanjang koridor Jalan Kom Yos Sudarso Pontianak yang merupakan salah satu jalan utama di Kota Pontianak untuk melihat kesesuaiannya dengan peraturan tata ruang dan bangunan yang berlaku khususnya peraturan yang berkaitan dengan perencanaan RMJ dan GSB pada kawasan tersebut.

Penelitian ini dilakukan dengan observasi dan pengamatan langsung di lapangan untuk memperoleh data primer berkaitan dengan jumlah serta karakteristik bangunan yang ada di sepanjang koridor Jalan Kom. Yos Sudarso Pontianak. Bangunan yang diamati adalah seluruh bangunan di sepanjang ruas jalan yang menghadap langsung jalan Kom. Yos Sudarso serta bangunan yang memiliki akses langsung ke jalanan Kom. Yos Sudarso.

Unit amatan dalam penelitian ini adalah sesuai dengan objek yang diamati yaitu aktivitas mendirikan bangunan di wilayah pengamatan. Oleh karena itu dalam penelitian ini akan mencoba 
menggambarkan secara detail mengenai aktivitas mendirikan bangunan di wilayah pengamatan. Variabel yang diamati tekait dengan aktivitas mendirikan bangunan yang memanfaatkan ruang di sepanjang koridor Jalan Kom. Yos sudarso Pontianak antara lain: fungsi bangunan, kegunaan bangunan, jumlah lantai bangunan, serta jenis konstruksi bangunan. Selanjutnya penulis akan menganalisis kesesuai bangunan tersebut dengan peraturan penataan ruang dan bangunan khususnya kesesuaiannya dengan peraturan penataan RMJ dan GSB di wilayah pengamatan.

Dalam melakukan pengamatan tersebut, sumber data yang digunakan adalah dengan menggabungkan peta citra satelit serta peta ruas jalan eksisting di jalan Kom. Yos Sudarso. selanjutnya dilakukan pengamatan secara langsung di lapangan dengan melakukan pemetaan terhadap variabel amatan untuk aktivitas mendirikan bangunan di sepanjang koridor Jalan tersebut. Data-data yang sudah terkumpul, baik yang merupakan data sekunder maupun data primer yang diperoleh melalui survey lapangan selanjutkan akan dilakukan proses pengolahan data. Analisis yang digunakan adalah analisis deskriptif frekuensi untuk melihat pola sebaran. Dari analisis secara diskriptif ini maka akan diketahui tentang frekuensi, kecenderungan serta pola sebaran data aktivitas mendirikan bangunan di wilayah penelitian.

\section{Hasil Dan Pembahasan}

Lokasi penelitian terletak di Koridor Jalan Kom. Yos Sudarso yang berada di wilayah Kecamatan Pontianak Barat Kota Pontianak. Jalan Kom Yos. Sudarso adalah salah satu ruas jalan di Kota Pontianak yang merupakan jalan arteri dengan status jalan nasional di Kota Pontianak. yang memiliki panjang jalan mencapai $5.648 \mathrm{~m}$ yang batasannya mulai dari simpang Jalan Hasanudin hingga batas kota yang berbatasan dengan Kabupaten Kubu Raya. Wilayah administrasi penelitian dapat dilihat pada gambar 1 dan peta kondisi eksisting dapat dilihat pada gambar 2 berikut ini.

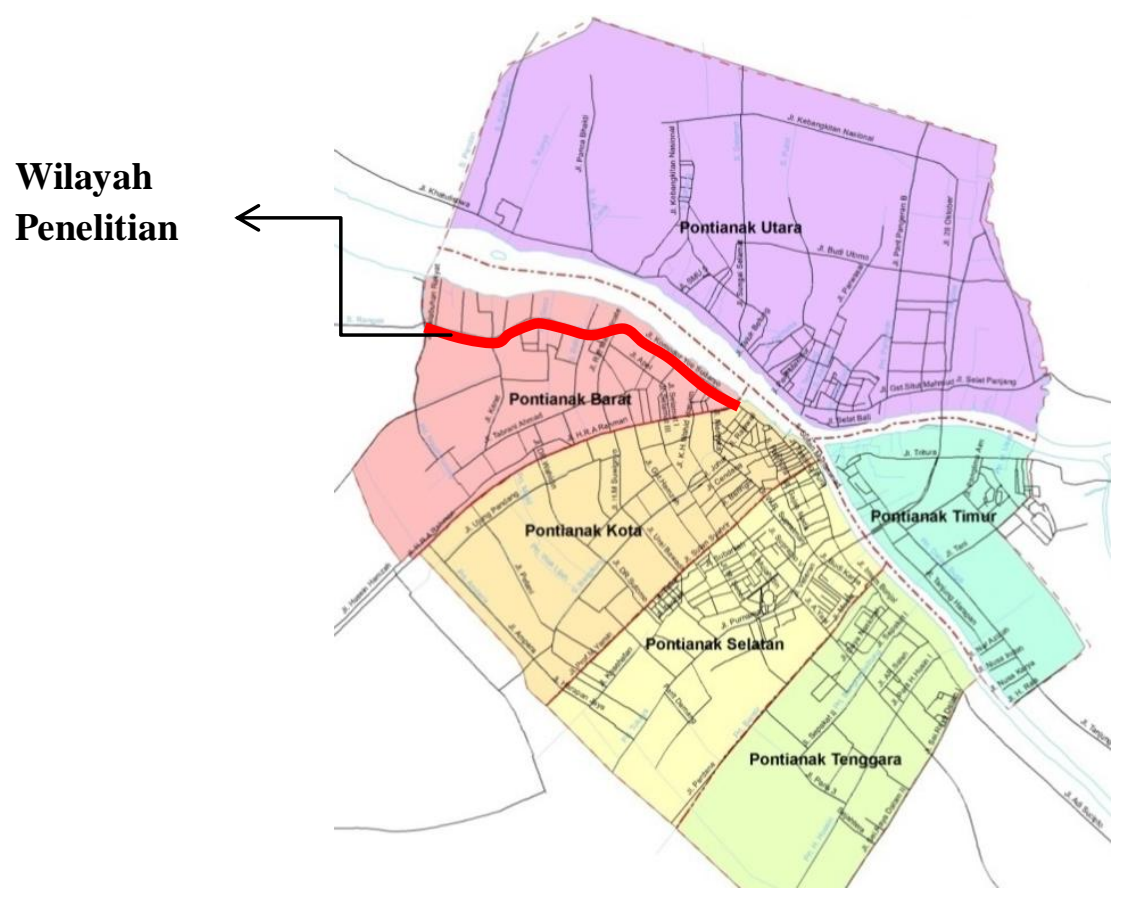

Gambar 1. Peta Adminstasi Wilayah Penelitian Sumber: Dinas PU dan Penataan Ruang Kota Pontianak, 2017 


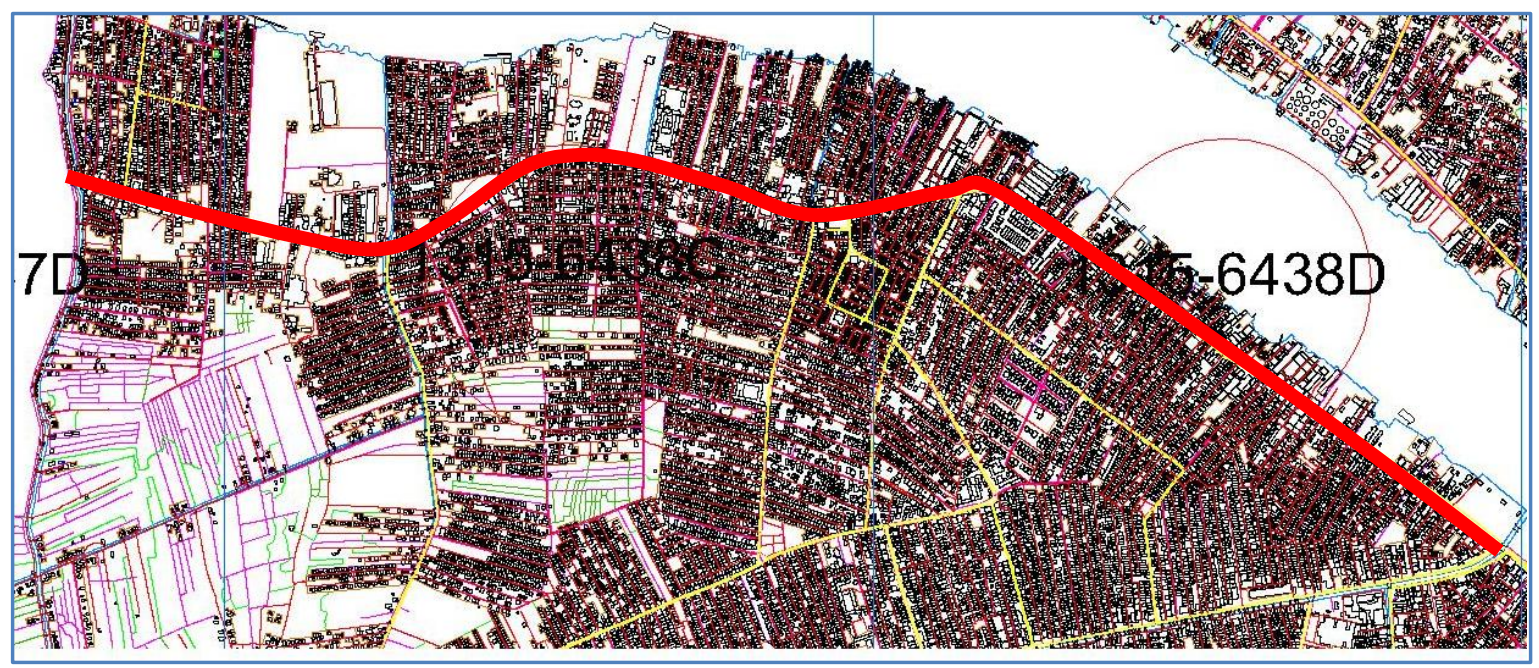

Gambar 2. Peta Kondisi Eksisting Wilayah Penelitian

Sumber: Dinas PU dan Penataan Ruang Kota Pontianak, 2017

Berdasarkan data yang diperoleh yaitu peta jalan eksisting, lebar pekerasan jalan bervariasi mulai dari yang lebarnya 8 meter hingga mencapai 16 meter sesuai dengan perencanaan. Hal ini terjadi karena pekerjaan pelebaran jalan masih belum sepenuhnya selesai di lakukan oleh Pemerintah Kota Pontianak serta dilakukan secara bertahap di sepanjang ruas jalan ini.

Untuk melihat perkembangan jalan Kom. Yos Sudarso saat ini, maka guna lebih memudahkan dalam melakukan pengamatan pada penelitian ini ruas jalan yang ada yang mencapai 5,648 kilometer berdasarkan jaraknya dibagi menjadi 16 segmen yang dimulai dari persimpangan jalan Hasanuddin hingga batas kota di Kabupaten Kubu Raya. Untuk melihat wilayah pembagian segmennya dapat dilihat pada tabel 1 berikut ini.

Tabel 1. Pembagian Segmen Jalan Kom. Yos Sudarso Pontianak

\begin{tabular}{|c|c|c|}
\hline No & Nama Segmen & Batas Segemen \\
\hline 1 & Segmen 1 & Mulai dari simpang jalan Hasanuddin s/d gang Langgar \\
\hline 2 & Segmen 2 & Mulai dari gang Langgar s/d gang Kelontan \\
\hline 3 & Segmen 3 & Mulai dari gang Kelontan s/d gang Kedondong \\
\hline 4 & Segmen 4 & Mulai dari gang Kedondong s/d parit dekat gang Ridan \\
\hline 5 & Segmen 5 & Mulai dari parit dekat gang Ridan s/d Komplek TNI AL \\
\hline 6 & Segmen 6 & Mulai dari Komplek TNI AL s/d Gang Pandu \\
\hline 7 & Segmen 7 & Mulai dari gang Pandu s/d Gang Gotong Royong I \\
\hline 8 & Segmen 8 & Mulai dari gang Gotong Royong I s/d gang Kasuari \\
\hline 9 & Segmen 9 & Mulai dari gang Kasuari s/d gang Triputri \\
\hline 10 & Segmen 10 & Mulai dari gang Triputri s/d jalan Atot Ahmad \\
\hline 11 & Segmen 11 & Mulai dari jalan Atot Ahmad s/d dekat Alpokat Permai \\
\hline 12 & Segmen 12 & Mulai dari Alpokat Permai s/d Komp. Jeruju Permai II \\
\hline 13 & Segmen 13 & Mulai dari Komplek Jeruju Permai II s/d rumah sakit kota \\
\hline 14 & Segmen 14 & Mulai dari rumah sakit kota s/d gang Sapta Marga \\
\hline 15 & Segmen 15 & Mulai dari gang Sapta Marga s/d Pasar Nipah Kuning \\
\hline 16 & Segmen 16 & Mulai dari pasar nipah kuning s/d Batas Kota \\
\hline
\end{tabular}

Sumber: Dinas PU dan Penataan Ruang Kota Pontianak, 2017 
Untuk melihat pembagian segemen di ruas jalan Kom. Yos Sudarso dapat dilihat pada gambar 3 peta pembagian segmen jalan Kom. Yos Sudarso berikut ini.

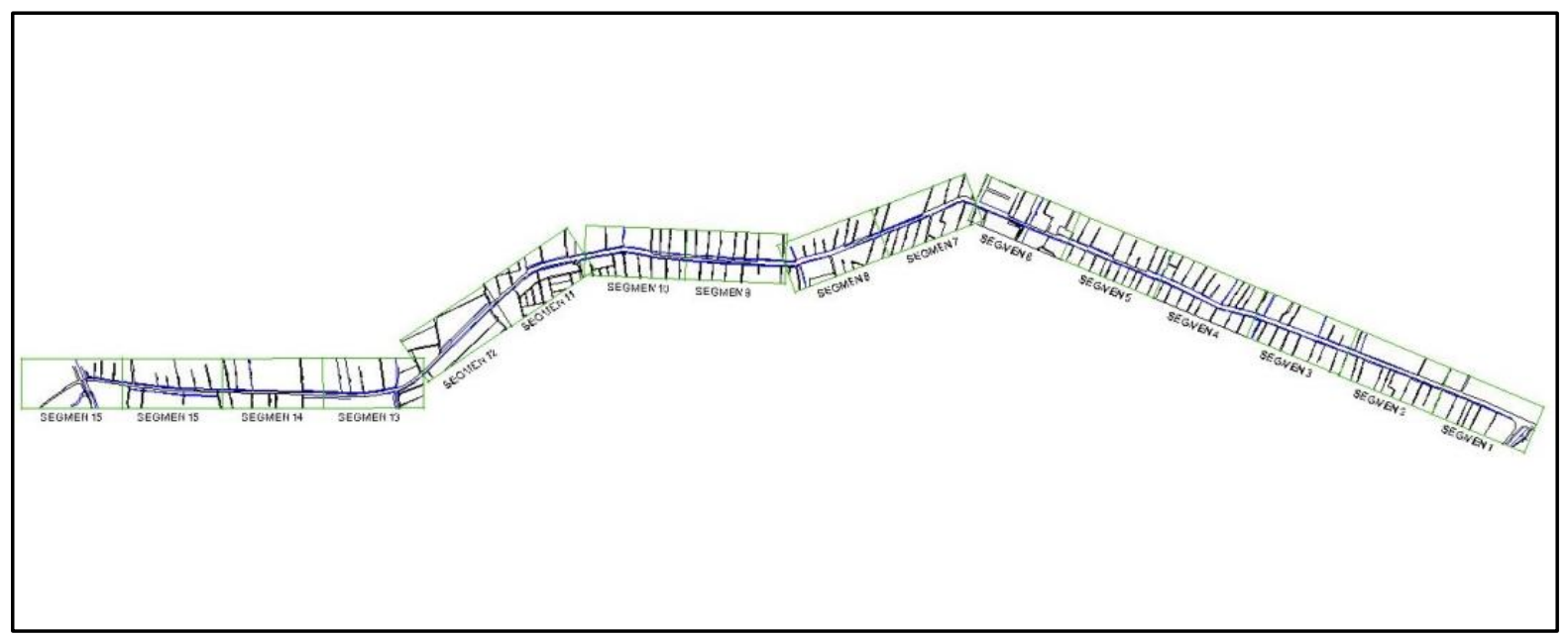

Gambar 3. Peta Pembagian Segmen Wilayah Penelitian

Sumber: Penulis, 2017

Adapun karakteristik bangunan di sepanjang koridor jalan Kom Yos Sudarso ini dibahas pada kajian-kajian dibawah ini.

\section{Fungsi Bangunan}

Fungsi bangunan di sepanjang koridor Jalan Kom Yos Sudarso terdiri dari bangunan yang berfungsi khusus sebagai tempat hunian, fungsi hunian sekaligus usaha, fungsi keagamaan, fungsi sosial dan budaya serta bangunan yang murni berfungsi sebagai tempat usaha. Berdasarkan hasil pengolahan data terhadap Fungsi Bangunan di sepanjang koridor Jalan Kom Yos Sudarso dapat dilihat distribusinya pada tabel 2 dan grafik frekuensinya pada gambar 4 berikut ini.

Tabel 2. Frekuensi Distribusi Berdasarkan

Fungsi Bangunan

\begin{tabular}{l|l|l}
\hline Fungsi Bangunan & Jumlah & Persen (\%) \\
\hline Hunian & 158 & 12,6 \\
\hline Hunian dan Usaha & 240 & 19,1 \\
\hline Keagamaan & 10 & 0,8 \\
\hline Sosial dan Budaya & 37 & 2,9 \\
\hline Usaha & 813 & 64,6 \\
\hline Total & $\mathbf{1 . 2 5 8}$ & $\mathbf{1 0 0 , 0}$ \\
\hline
\end{tabular}

Sumber: Hasil Identifikasi, 2017 


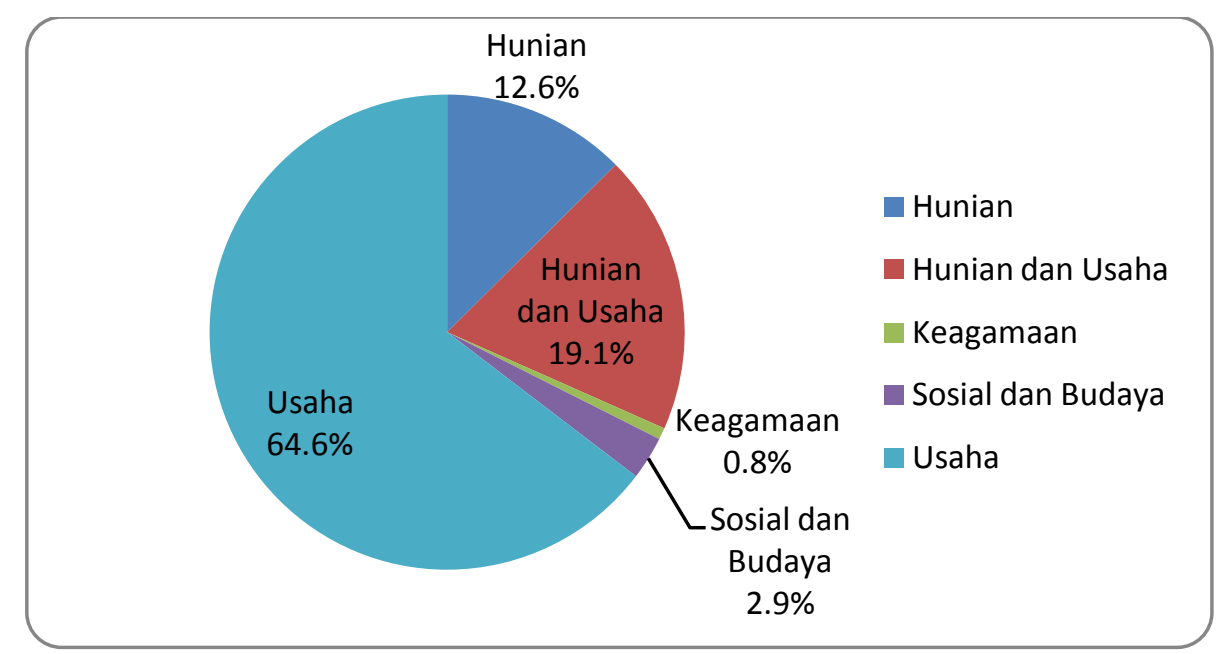

Gambar 4. Grafik Frekuensi Bangunan Berdasarkan Fungsinya

Sumber: Hasil Identifikasi, 2017

Dari data di atas terlihat bahwa fungsi bangunan yang paling dominan pada bangunan bangunan di wilayah penelitian ini adalah fungsi bangunan yang berfungsi sebagai tempat usaha yang mencapai 813 unit bangunan atau 64,6 \% yang kemudian disusul dengan bangunan dengan fungsi hunian sekaligus usaha yang mencapai 19, $1 \%$ dari jumlah seluruh unit bangunan yang diamati.Untuk bangunan dengan fungsi sebagai hunian saja berada pada urutan ketiga terbanyak yang mencapai $12,6 \%$. Sementara itu bangunan dengan fungsi sosial dan budaya jumlahnya relatif sedikit yakni 2,9\% dari total bangunan yang diamati. Dari hasil pengolahan data dapat diketahui bahwa bangunan dengan fungsi keagamaan adalah bangunan dengan jumlah paling sedikit pada wilayah pengamatan yang mencapai $0,8 \%$ dari seluruh bangunan yang diamati yang berjumlah 1.258 unit.

Dari hasil pengolahan data yang lebih detail dapat diketahui bahwa jumlah sebaran bangunan sebagai fungsi usaha yang terbesar berada pada segmen 5 yaitu berjumlah 72 unit dari total bangunan yang mencapai 106 unit. Sementara untuk penyebaran bangunan dengan fungsi usaha terkecil berada pada wilayah segemen 2 yang berjumlah 25 unit bangunan. Selain itu fungsi hunian sekaligus digunakan sebagai fungsi usaha juga menunjukan jumlah yang cukup besar di sepanjang koridor jalan Kom Yos Sudarso. Secara keseluruhan melihat data yang ada dapat ditarik kesimpulan bahwa di sepanjang koridor jalan Kom Yos Sudarso ini di dominasi oleh fungsi usaha serta fungsi hunian sekaligus sebagai fungsi usaha.

\section{Kegunaan Bangunan}

Kegunaan bangunan yang ada di sepanjang koridor jalan Kom. Yos Sudarso dari hasil pengamatan yang sudah dilakukan sangat beragam sesuai dengan fungsi bangunannya. Berdasarkan hasil pengolahan data terhadap Kegunaan Bangunan di sepanjang koridor Jalan Kom Yos Sudarso dapat dilihat distribusinya pada tabel 3 berikut.

Tabel 3. Frekuensi Distribusi Berdasarkan Kegunaan Bangunan

\begin{tabular}{lcc}
\hline Kegunaan Bangunan & Jumlah & Persen (\%) \\
\hline bangsal & 17 & 1,4 \\
\hline gereja & 2 & 0,2 \\
\hline gudang & 34 & 2,7 \\
\hline hotel/ wisma & 1 & 0,1 \\
\hline kantor & 15 & 1,2 \\
\hline Kantor PM AL & 1 & 0,1
\end{tabular}




\begin{tabular}{lcc}
\hline Kegunaan Bangunan & Jumlah & Persen $(\boldsymbol{\%})$ \\
\hline kantor polsek & 3 & 0,2 \\
\hline kantor pos & 1 & 0,1 \\
\hline Kantor TNI AL & 1 & 0,1 \\
\hline kios & 379 & 30,1 \\
\hline masjid & 7 & 0,6 \\
\hline pasar tradisional & 2 & 0,2 \\
\hline pom bensin & 2 & 0,2 \\
\hline pos jaga & 2 & 0,2 \\
\hline pos pemadam kebakaran & 1 & 0,1 \\
\hline ruko & 297 & 23,6 \\
\hline rumah tinggal & 158 & 12,6 \\
\hline rumah tinggal dan usaha & 130 & 10,3 \\
\hline rusunawa & 1 & 0,1 \\
\hline sekolah & 4 & 0,3 \\
\hline sekolah sd & 8 & 0,6 \\
\hline sekolah smk & 3 & 0,2 \\
\hline sekolah tk & 1 & 0,1 \\
\hline supermarket & 2 & 0,2 \\
\hline surau & 3 & 0,2 \\
\hline tempat usaha & 110 & 8,7 \\
\hline toko & 72 & 5,7 \\
\hline universitas & 1 & 0,1 \\
\hline Total & $\mathbf{1 . 2 5 8}$ & $\mathbf{1 0 0 , 0}$ \\
\hline
\end{tabular}

Sumber: Hasil Identifikasi, 2017

Dari tabel di atas dapat dilihat kegunaan bangunan yang terbesar di Jalan Kom. Yos Sudarso adalah bangunan yang digunakan untuk fungsi usaha yaitu bangunan berbentuk kios yang berjumlah 379 unit bangunan atau mencapai 30,1 \% . Selain itu guna bangunan RUKO yang digunakan sebagai bangunan dengan fungsi usaha dan hunian juga menunjukan jumlah yang besar yang mencapai 297 unit bangunan atau sebesar 23,6 \% dari seluruh bangunan yang diamati. Dari hasil pengolahan data yang lebih detail juga dapat diketahui bahwa kegunaan bangunan yang mendominasi adalah bangunan dengan fungsi usaha yang kegunaan bangunanya berupa RUKO dan kios. Sebaran RUKO terbanyak berada pada segmen 3 yang mencapai 51 unit dan sebaran kios terbanyak berada pada segemen 16 yang mencapai 52 unit.

\section{Jumlah Lantai Bangunan}

Ketinggian bangunan bisa dilihat dari jumlah lantai yang ada pada bangunan tersebut. Berdasarkan hasil pengolahan data terhadap jumlah lantai bangunan di sepanjang koridor Jalan Kom Yos Sudarso dapat dilihat distribusinya pada tabel 4 dan grafik frekuensinya pada gambar 5 berikut ini.

Tabel 4. Frekuensi Distribusi Berdasarkan Jumlah Lantai Bangunan

\begin{tabular}{l|l|l}
\hline $\begin{array}{l}\text { Jumlah Lantai } \\
\text { Bangunan }\end{array}$ & Jumlah & Persen (\%) \\
\hline 1 Lantai & 715 & 56,8 \\
\hline 2 Lantai & 407 & 32,4 \\
\hline 3 Lantai & 131 & 10,4
\end{tabular}




\begin{tabular}{l|l|l} 
4 Lantai & 4 & 0,3 \\
\hline 5 Lantai & 1 & 0,1 \\
\hline Total & $\mathbf{1 . 2 5 8}$ & $\mathbf{1 0 0 , 0}$ \\
\hline \multicolumn{2}{r}{ Sumber: Hasil Identifikasi, } & 2017
\end{tabular}

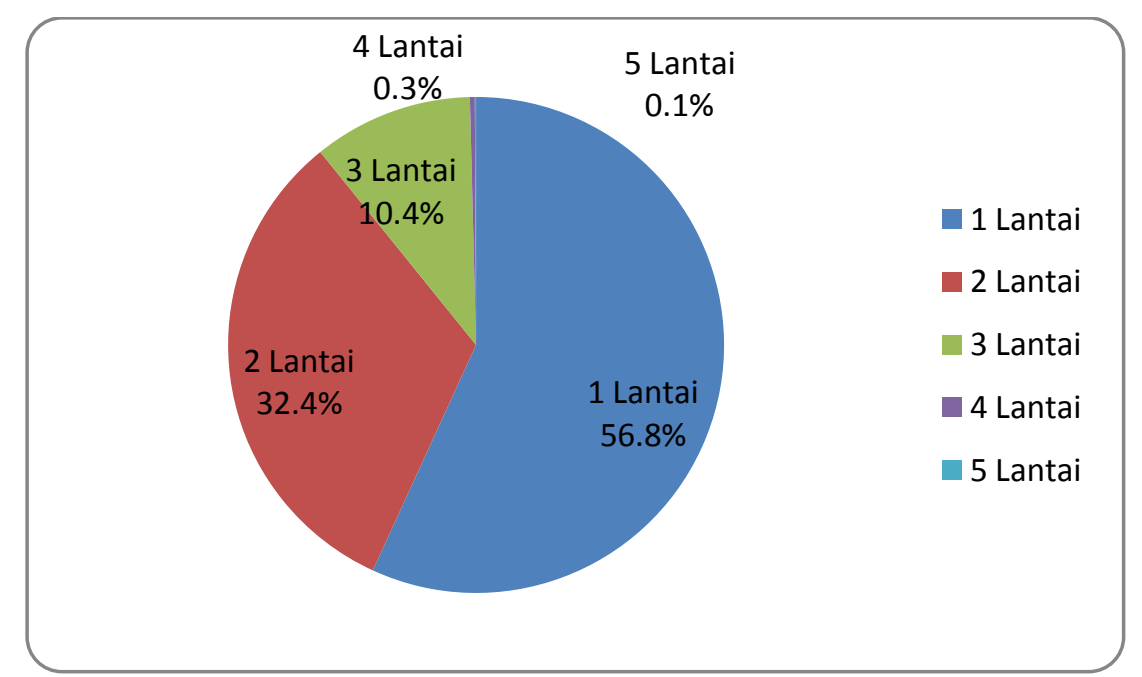

Gambar 5. Grafik Frekuensi Distribusi Berdasarkan Jumlah Lantaidi Wilayah Penelitian Sumber: Hasil Identifikasi, 2017

Jika melihat data pada tabel di atas, bangunan-bangunan di koridor jalan Kom Yos Sudarso yang paling dominan adalah bangunan 1 lantai yang berjumlah 715 unit bangunan atau 56,8\% dari total bangunan yang ada di koridor jalan tersebut. Sedangkan bangunan yang memiliki jumlah lebih dari 3 lantai hanya mencapi 5 unit saja atau 0,4\% dari total keseluruhan bangunan yang ada di sepanjang koridor jalan Kom. Yos Sudarso.

Untuk data yang lebih detail juga dapat diketahui bahwa bangunan dengan ketinggian rendah yakni dengan 1 lantai begitu mendominasi pada koridor jalan Kom. Yos Sudarso ini dengan sebaran terbanyak pada segemen 5 yang mencapai 68 unit. Untuk bangunan tertinggi dengan 5 lantai hanya terdiri dari 1 unit saja yaitu berada pada segemen 9.

\section{Jenis Konstruksi Bangunan}

Jenis konstruksi bangunan di sepanjang koridor jalan Kom. Yos Sudarso terdiri darai jenis konstruksi bangunan permanen, semi permanen dan darurat. Berdasarkan pengamatan dan hasil pengolahan data terhadap Jenis Konstruksi bangunan di sepanjang koridor Jalan Kom Yos Sudarso dapat dilihat distribusinya pada tabel 5 serta grafik frekuensinya pada gambar 6 berikut.

Tabel 5. Frekuensi Distribusi Berdasarkan Jenis Konstruksi Bangunan

\begin{tabular}{l|l|l}
\hline $\begin{array}{l}\text { Jenis Konstruksi } \\
\text { Bangunan }\end{array}$ & Jumlah & Persen (\%) \\
\hline Darurat & 70 & 5,60 \\
\hline Permanen & 290 & 23,00 \\
\hline Semi Permanen & 898 & 71,40 \\
\hline Total & $\mathbf{1 . 2 5 8}$ & $\mathbf{1 0 0 , 0 0}$ \\
\hline
\end{tabular}

Sumber: Hasil Identifikasi, 2017 


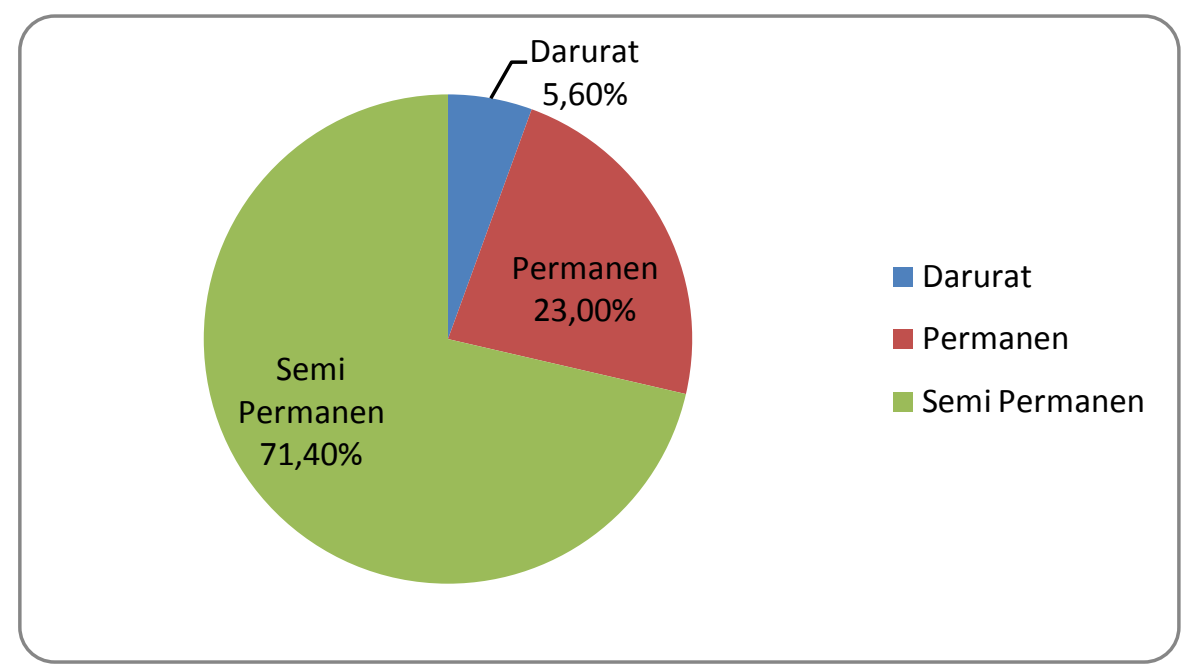

Gambar 6. Grafik Frekuensi Bangunan Berdasarkan Jenis Konstruksi di Wilayah Penelitian Sumber: Hasil Identifikasi, 2017

Dari data di atas dapat dilihat bahwa jenis konstruksi bangunan yang digunakan oleh bangunan yang berdiri di sepanjang koridor jalan Kom Yos Sudarso sebagian besar menggunakan jenis konstruksi semi permanen. Jumlah bangunan yang menggunakan jenis konstruksi banguan semi permanen tersebut mencapai 898 unit bangunan atau 71,40\% dari total seluruh unit bangunan di sepanjang koridor Jalan Kom Yos Sudarso. Dari data yang lebih detail dapat diketahui bahwa bangunan dengan konstruksi semi permanen begitu mondominasi. Sebaran terbanyak berada pada segemen 9 yang mencapai 88 unit. Untuk bangunan dengan konstruksi permanen yang terbanyak berada pada segemen 6 yang mencapai 55 unit. Sementara untuk bangunan dengan konstruksi darurat sebaran terbanyak berada pada segemen 16 yang mencapai 23 unit.

\section{Kesesuaian Bangunan Terhadap peraturan RMJ dan GSB}

Salah satu bentuk dari persayaratan perizinan bagi pemanfaatan ruang adalah kesesuaian antara aktivitas mendirikan bangunan dengan peraturan mengenai ketetapan RMJ (Ruang Milik Jalan) dan GSB (Garis Sempadan Bangunan) di Koridor Jalan Kom. Yos Sudarso Pontianak. Dari aturan penataan bangunan di sepanjang koridor Jalan Kom Yos penataan RMJ pada ruas jalan ini ditetapkan 22 (dua puluh dua) meter. Sementara untuk penetapan GSB di sepanjang koridor jalan ini peraturannya adalah untuk wilayah dari simpang jalan Hasanuddin sampai dengan jalan Karet adalah 7,00 meter untuk sebelah utara dan 12,00 meter dari ruang milik jalan, sedangkan untuk wilayah dari simpang jalan karet sampai dengan batas kota, GSB yang ditetapkan adalah 12,00 meter untuk sebelah utara dan 7,00 meter untuk sebelah selatan dari ruang milik jalan.

Berdasarkan hasil tumpang susun peta eksisting bangunan dan peta penataan Ruang Milik Jalan (RMJ) di koridor jalan kom. Yos Sudarso serta hasil pengolahan data analisis maka dapat dilihat kesesuian bangunan terhadap penataan RMJ pada tabel 6 dandan grafik frekuensi distribusinya pada Gambar 7 berikut ini.

Tabel 6. Frekuensi Distribusi Berdasarkan Kesesuaian Bangunan terhadap RMJ

\begin{tabular}{l|l|l}
\hline Kesesuaian Bangunan & Jumlah & Persen (\%) \\
\hline Melanggar & 216 & 17,2 \\
\hline Sesuai & 1.042 & 82,8 \\
\hline Total & 1.258 & 100,0 \\
\hline
\end{tabular}

Sumber: Hasil Identifikasi, 2017 


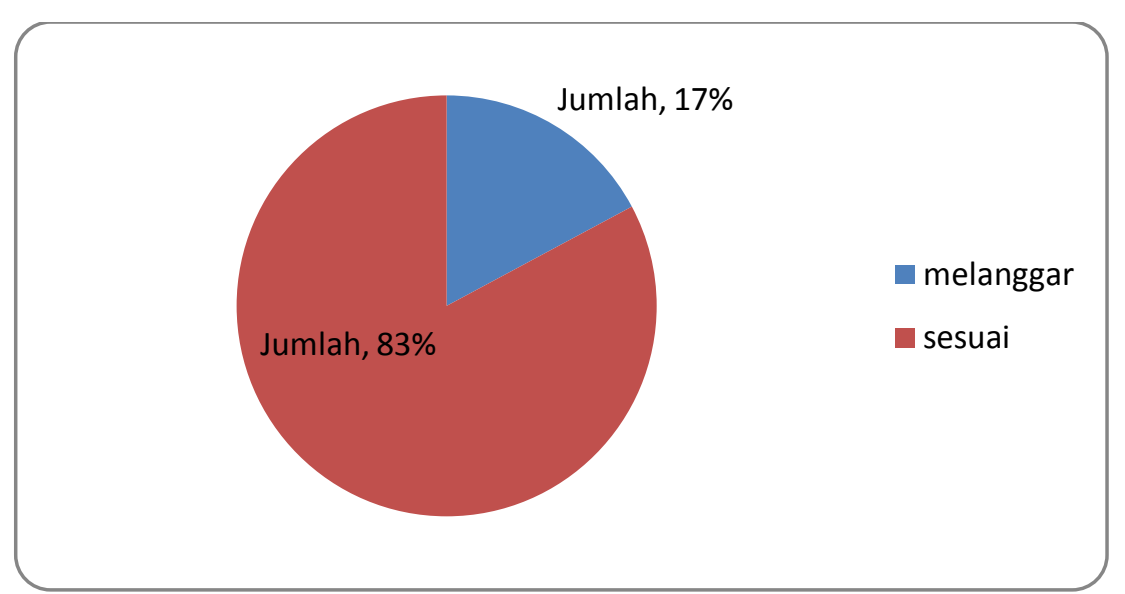

\section{Gambar 7. Grafik Distribusi Bangunan Berdasarkan Kesesuaian Penataan RMJ Pada Wilayah Penelitian \\ Sumber: Hasil Identifikasi, 2017}

Dari data hasil analisis di atas dapat dilihat bahwa masih banyak terdapat bangunan yang melanggar peraturan RMJ yang berjumlah 216 unit bangunan atau 17,2 \% dari total seluruh bangunan yang diamati di sepanjang koridor jalan Kom Yos Sudarso. Berdasarkan hasil pengolahan data dari peta kesesuian fungsi bangunan terhadap peraturan penataan RMJ di sepanjang koridor jalan Kom. Yos Sudarso dapat dilihat pada uraiannya pada tabel 7 berikut ini.

Tabel 7. Kesesuaian Fungsi Bangunan Terhadap RMJ

\begin{tabular}{lrrr}
\multirow{2}{*}{$\begin{array}{l}\text { Fungsi } \\
\text { Bangunan }\end{array}$} & \multicolumn{2}{c}{$\begin{array}{l}\text { Kesesuaian } \\
\text { Terhadap RMJ }\end{array}$} & \multicolumn{1}{l}{ Total } \\
\cline { 2 - 3 } Hunian & melanggar & \multicolumn{1}{c}{ sesuai } & \\
\hline \multirow{2}{*}{ hunian dan usaha } & 9 & 149 & 158 \\
\cline { 2 - 4 } & $0,70 \%$ & $11,80 \%$ & $12,60 \%$ \\
\hline \multirow{2}{*}{ keagamaan } & $1,40 \%$ & $17,60 \%$ & $19,10 \%$ \\
\hline \multirow{2}{*}{ sosial dan budaya } & 2 & 8 & 10 \\
\cline { 2 - 4 } & $0,20 \%$ & $0,60 \%$ & $0,80 \%$ \\
\hline \multirow{2}{*}{ Usaha } & 1 & 36 & 37 \\
\hline \multirow{2}{*}{ Total } & $10,10 \%$ & $2,90 \%$ & $2,90 \%$ \\
\cline { 2 - 4 } & $14,80 \%$ & 627 & 813 \\
\hline
\end{tabular}

Sumber: Hasil Identifikasi, 2017

Dengan melihat data di atas bahwa tingkat pelanggaran tertinggi terhadap RMJ terdapat pada bangunan dengan fungsi usaha yang mencapai 186 unit atau 14,80\% dari jumlah keseluruhan bangunan yang di amati pada koridor jalan Kom. Yos Sudarso Pontianak. Dengan melihat pola sebaran pada peta analisis kesesuaian RMJ maka dapat diketahui sebaran bangunan yang melanggar tadi berada pada beberapa wilayah segemen. Wilayah yang terbanyak melanggar RMJ adalah pada wilayah segemen 15 dan 16 yaitu terdapat 32 unit kios yang rata-rata merupakan bangunan darurat yang berlokasi di sekitar pasar terminal nipah kuning. 
Dari peta kesesuaian bangunan dengan GSB serta hasil analisis pengolahan data terhadap bangunan eksisting dan penataan GSB di sepanjang koridor jalan dapat dilihat pada tabel 8 dan frekuensi distribusinya pada gambar 8 berikut.

Tabel 8. Frekuensi Distribusi Berdasarkan Kesesuaian Bangunan terhadap GSB

\begin{tabular}{l|r|r}
\hline $\begin{array}{c}\text { Kesesuian } \\
\text { Bangunan }\end{array}$ & Jumlah & Persen (\%) \\
\hline melanggar & 825 & 65,6 \\
\hline sesuai & 433 & 34,4 \\
\hline Total & 1.258 & 100,0 \\
\hline \multicolumn{2}{r|}{ Sumber: Hasil Identifikasi, 2017} \\
\hline
\end{tabular}

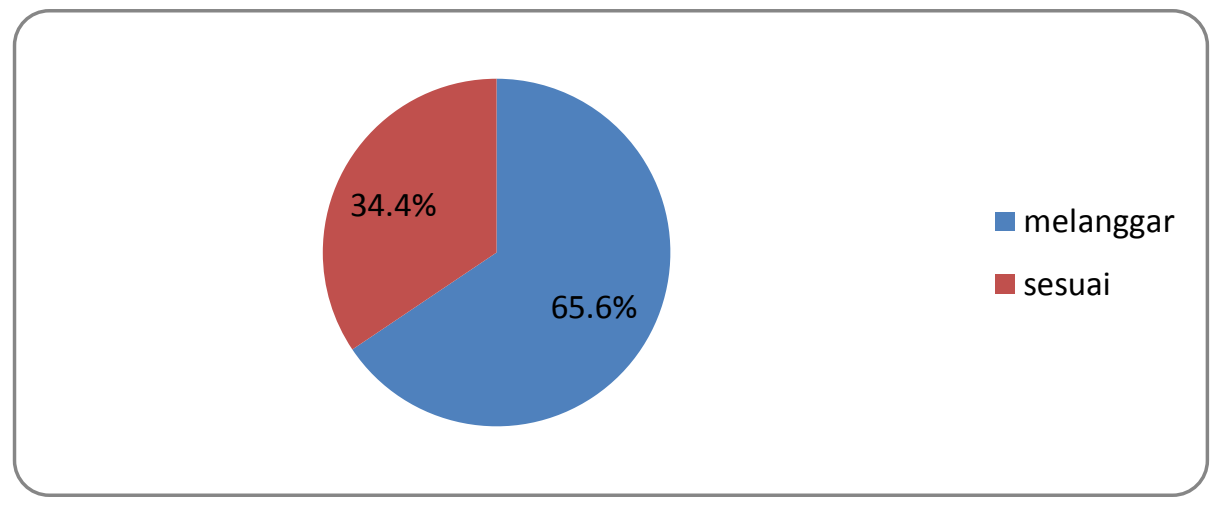

Gambar 8. Grafik Freksuensi Distribusi Berdasarkan Kesesuian Bangunan Terhadap GSB di Wilayah Penelitian

Sumber: Hasil Identifikasi, 2017

Apabila memperhatikan dari data di atas, terlihat banyak bangunan-bangunan yang berdiri di sepanjang koridor jalan Kom Yos Sudarso ini yang melanggar GSB yaitu mencapai 65,6 \% dari total bangunan yang diamati. Dari hasil analisis pengolahan data jumlah bangunan yang melanggar GSB ini mencapai 825 unit bangunan. Dari data serta hasil analisis pengolahan data kesesuaian fungsi bangunan terhadap GSB dapat dilihat pada tabel 9 di bawah ini.

Tabel 9. Kesesuaian Fungsi Bangunan Terhadap GSB

\begin{tabular}{|c|c|c|c|}
\hline \multirow{2}{*}{$\begin{array}{l}\text { Fungsi } \\
\text { Bangunan }\end{array}$} & \multicolumn{2}{|c|}{ Kesesuian Terhadap GSB } & \multirow{2}{*}{ Total } \\
\hline & melanggar & sesuai & \\
\hline \multirow{2}{*}{ hunian } & 99 & 59 & 158 \\
\hline & $7,90 \%$ & $4,70 \%$ & $12,60 \%$ \\
\hline \multirow{2}{*}{$\begin{array}{l}\text { hunian dan } \\
\text { usaha }\end{array}$} & 180 & 60 & 240 \\
\hline & $14,30 \%$ & $4,80 \%$ & $19,10 \%$ \\
\hline \multirow{2}{*}{ keagamaan } & 7 & 3 & 10 \\
\hline & $0,60 \%$ & $0,20 \%$ & $0,80 \%$ \\
\hline \multirow{2}{*}{$\begin{array}{l}\text { sosial dan } \\
\text { budaya }\end{array}$} & 12 & 25 & 37 \\
\hline & $1,00 \%$ & $2,00 \%$ & $2,90 \%$ \\
\hline
\end{tabular}




\begin{tabular}{lrrr}
\multirow{2}{*}{$\begin{array}{l}\text { Fungsi } \\
\text { Bangunan }\end{array}$} & \multicolumn{2}{c}{ Kesesuian Terhadap GSB } & \multirow{2}{*}{ Total } \\
\cline { 2 - 3 } & melanggar & \multicolumn{2}{c}{ sesuai } \\
\hline \multirow{2}{*}{ usaha } & 527 & 286 & 813 \\
\hline \multirow{2}{*}{ Total } & $41,90 \%$ & $22,70 \%$ & $64,60 \%$ \\
\hline
\end{tabular}

Sumber: Hasil Identifikasi, 2017

Dari hasil analisis di atas dapat dilihat bahwa fungsi bangunan yang paling banyak melanggar aturan penataan GSB adalah bangunan dengan fungsi usaha serta bangunan yang berfungsi sebagai hunian dan usaha yang mencapai $41,9 \%$ dan $14,3 \%$ dari total bangunan yang di amati.

\section{Kesimpulan}

Dari hasil identifikasi terhadap pemanfaatan ruang bagi aktivitas mendirikan bangunan di sepanjang koridor jalan Kom. Yos Sudarso Pontianak yang mencapai 1.258 unit ini memiliki fungsi, guna bangunan, ketinggian lantai dan konstruksi bangunan yang beragam. Secara keseluruhan untuk fungsi bangunan di wilayah penelitian dari hasil pengolahan data, didominasi oleh fungsi usaha yang mencapai 64,4 \% yang guna bangunannya terbanyak adalah untuk kios yang mencapai 30,1\% dari seluruh bangunan yang diamati. Untuk ketinggian bangunan di wilayah pengamatan secara keseluruhan didominasi oleh bangunan dengan ketinggian rendah yaitu 1 lantai yang mencapai 56,8 \%. Berdasarkan konstruksi bangunannya, rata-rata adalah bangunan yang berdiri di koridor Jalan Kom. Yos Sudarso ini adalah bangunan dengan konstruksi semi permanen yang mencapai 71, $4 \%$ dari total bangunan yang diamati. Salah satu persyaratan perizinan bagi aktivitas mendirikan bangunan di sepanjang koridor Jalan Kom. Yos Sudarso ini adalah kesesuaian bangunan tersebut terhadap penetapan peraturan RMJ dan GSB. Dari hasil penelitian terhadap penerapan aturan tersebut terlihat cukup banyak bangunan yang menyimpang serta melanggar peraturan yang ada, dengan demikian bangunan yang didirikan tersebut tidak sesuai ketentuan dan melanggar peraturan peizinan bangunan. Setelah melakukan pengolahan data dalam penelitian ini terdapat 216 unit bangunan atau 17,2 \% terkena perencanaan RMJ yang sebagian besar adalah bangunan dengan fungsi usaha. Sementara itu bangunan yang tidak sesuai dengan penataan GSB pada wilayah penelitian ini sebesar 825 unit bangunan atau mencapai 65,6 \% dari seluruh bangunan yang diamati.

\section{Daftar Pustaka}

Irawati, H.,Haryanto, R. (2015). Perubahan Fungsi Lahan Koridor Jalan Selokan Mataram Kabupaten Sleman. Jurnal Teknik PWK Vol. 4 No. 2 (2015)

Kementerian Hukum dan HAM RI. (2007). Undang Undang Nomor 26 Tahun 2007 Tentang Penataan Ruang. Kementerian Hukum dan HAM RI. Jakarta

Kementerian Hukum dan HAM RI. (2002). Undang Undang Nomor 28 Tahun 2002 Tentang Bangunan Gedung

Kementerian Pekerjaan Umum RI. (2007). Peraturan Menteri Pekerjaan Umum Nomor: 06/PRT/M/2007 Tanggal 16 Maret 2007 Tentang Pedoman Umum Rencana Tata Bangunan Dan Lingkungan. Kementerian Pekerjaan Umum RI. Jakarta

Nurmandi, A. (1999), Manajemen Perkotaan. Lingkaran Bangsa. Yogyakarta
Sekretariat Daerah Kota Pontianak. (2008). Peraturan Daerah Kota Pontianak No. 3 Tahun 2008 tentang Bangunan Gedung. Sekretariat Daerah Kota Pontianak. Pontianak

Sekretariat Daerah Kota Pontianak. (2013). Peraturan Daerah Kota Pontianak No. 2 Tahun 2013 tentang RTRW Kota Pontianak. Sekretariat Daerah Kota Pontianak. Pontianak

Wardhana, I, W., Haryanto, R. (2016). Kajian Pemanfaatan Ruang Kegiatan Komersial Koridor Jalan Taman Siswa Kota Semarang . Jurnal Pengembangan Kota Volume 4 No. 1 : 49-57 (2016)

Yahya, M. (2015). Kajian Tata Bangunan dan Lingkungan pada Koridor Jalan Perintis Kemerdekaan Kota Makassar. Prosiding Temu Ilmiah IPLBI 2015. B.033-B.038 